\title{
The effect of improved reproductive performance on genetic gain and inbreeding in MOET breeding schemes for beef cattle
}

\author{
B Villanueva ${ }^{1}, \mathrm{JA} \mathrm{Woolliams}^{2}, \mathrm{G} \mathrm{Simm}^{1}$ \\ ${ }^{1}$ Scottish Agricultural College, West Mains Road, Edinburgh, EH9 $3 J G$; \\ ${ }^{2}$ Roslin Institute (Edinburgh), Roslin, Midlothian, EH25 9PS, UK
}

(Received 9 November 1994; accepted 6 March 1995)

\begin{abstract}
Summary - The effect of improved reproductive techniques on genetic progress and inbreeding was investigated in MOET (multiple ovulation and embryo transfer) schemes for beef cattle. Stochastic simulation was used to model a closed scheme with overlapping generations. Selection was on a trait measured in both sexes, with heritability 0.35 , and was carried out for 25 years. The number of breeding animals was 9 sires and 18 donors. Embryo production was modelled using a Poisson distribution with the parameter distributed according to a gamma distribution. The mean number of transferable embryos per flush and per donor was 5.0, with a coefficient of variation of 1.28 and repeatability between flushes of 0.22 . This model was compared with models used in previous studies (fixed number of embryos per flush or variable number of embryos but with zero repeatability between flushes). The coefficient of variation and the repeatability of embryo yield influenced inbreeding rates. The rate of inbreeding was underestimated by up to $17 \%$ when variability of embryo production was ignored. Without a constraint on the number of calves born per year, improved success rates for embryo collection and embryo transfer technologies led to notable increases in genetic progress. However, the rate of inbreeding was also increased with improved techniques. When the number of calves born per year was fixed, genetic progress was maintained but inbreeding rates were substantially reduced (by up to 11\%) with improved techniques due to the opportunity of equalizing family sizes. There was no benefit from sexed semen with constrained number of calves per year.
\end{abstract}

beef cattle / MOET / embryo / genetic gain / inbreeding

Résumé - Effet de l'amélioration des techniques de reproduction sur le progrès génétique et sur la consanguinité dans des schémas MOET pour bovins à viande. Notre investigation avait pour but d'étudier l'effet de techniques de reproduction améliorées sur le progrès génétique et sur la consanguinité, dans le cadre de schémas MOET (ovulation multiple et transfert d'embryon) pour les bovins à viande. Grâce à une simulation stochastique, un schéma fermé a été modélisé avec générations chevauchantes. La sélection a été effectuée pendant une période de 25 ans, sur un caractère mesurable dans les 2 sexes, dont 
l'héritabilité était de 0,35. Les nombres de reproducteurs mâles et de donneuses étaient de 9 et 18 respectivement. La production d'embryons a été modélisée en utilisant une distribution de Poisson dont le paramètre avait une distribution gamma. Le nombre moyen d'embryons transférables recueillis par collecte et par donneuse était de 5,0 avec un coefficient de variation de 1,28 et avec une répétabilité de 0,22 entre collectes. Ce modèle a été comparé avec d'autres modèles utilisés dans des études antérieures (qui utilisaient un nombre déterminé d'embryons par collecte, ou un nombre variable d'embryons mais avec une répétabilité nulle entre collectes). Le coefficient de variation et la répétabilité de la production d'embryons influencent le taux de consanguinité. Si on ne tient pas compte de la variabilité de la production d'embryons, la sous-évaluation du taux de consanguinité peut atteindre 17\%. Sans contrainte sur le nombre de naissances de veaux par an, un plus grand pourcentage de réussite dans la collecte d'embryons et l'amélioration des technologies de transfert contribuent ensemble à augmenter considérablement le progrès génétique. Cependant, l'amélioration des techniques a aussi pour effet d'augmenter le taux de consanguinité. Quand le nombre de veaux nés par an est fixé, le progrès génétique peut être maintenu, tout en réduisant le taux de consanguinité (jusqu'à 13\%), en employant les techniques améliorées, à cause de la possibilité d'égaliser la taille des familles. Il n'y a aucun bénéfice à utiliser du sperme sexé quand le nombre de veaux par an est fixé.

bovin à viande / schéma à ovulation multiple et transfert d'embryon (MOET) / embryon / gain génétique / consanguinité

\section{INTRODUCTION}

The value of multiple ovulation and embryo transfer (MOET) in breeding schemes for increasing genetic gain has been widely studied in dairy cattle (see review by Dekkers, 1992; Ruane and Thompson, 1991) and to a lesser extent in beef cattle (Land and Hill, 1975; Gearheart et al, 1989; Keller et al, 1990; Wray and Simm, 1990) and sheep (Smith, 1986; Wray and Goddard, 1994). Early studies concentrated on extra genetic progress expected with MOET. More recent studies have also considered possible risks associated with the use of MOET techniques. By greatly increasing the numbers of progeny to be produced by individuals, genetic progress can be improved due to increased intensities of selection. However, the extra gains can be accompanied by increased inbreeding since fewer parents contribute to the next generation. The adverse effects of inbreeding (loss of genetic variability, loss of predictability of genetic gain and inbreeding depression) should be taken into account when optimum schemes for genetic improvement using reproductive technologies are investigated.

One of the main shortcomings in earlier studies was the assumption of constant family size, or the assumption of a variable family size, but with no correlation between the number of embryos produced in successive recoveries. In fact there is a wide range in the size of families following MOET and analyses of MOET data have indicated a non-zero repeatability of embryo production ( $e g$, Lohuis et al, 1993; Woolliams et al, 1995). The increase in the variance of embryo yield can lead to increased rates of inbreeding and reductions in genetic gain. Recently, Woolliams et al (1995) have proposed a mathematical model to describe the distributions of embryo yields observed in practice. The model includes repeatability (ie the 
assumption of zero correlation between flushes is removed) and describes very accurately the number of embryos obtained per donor and per flush. Villanueva et al (1994) have used this model in a simulation study to investigate different strategies for controlling rates of inbreeding in MOET breeding schemes for beef cattle. With current values of parameters describing success rates of reproductive technologies, rates of inbreeding were very high for schemes with 18 donors and 9 sires, even when the most efficient strategies for controlling inbreeding were used (factorial mating designs and selection on best linear unbiased prediction (BLUP) breeding values assuming an inflated heritability). In this paper we investigate rates of progress and inbreeding obtained when different models for simulating embryo production are utilized.

Advances in embryo manipulation techniques have been rapid in the past few years and these are likely to continue. One of the main problems in the practical application of embryo transfer in breeding programmes using superovulation is the high variability among donors in the number of embryos collected. This produces a high variance in family size which in turn leads to a high variance in the numbers selected from each family (and, therefore, high inbreeding). Research is being addressed at reducing this variability and increasing the mean number of embryos per collection. Embryo survival rates and frequency of collection are also likely to be improved. Luo et al (1994) have given both pessimistic and optimistic predictions for future success rates of embryological techniques. The effect that improved future success rates for embryo recovery and embryo transfer could have on rates of response and inbreeding is investigated in this paper. Also, the techniques for sexing of embryos or semen are already used on a small scale. Semen and embryo sexing may become commercial in the near future and so the value of sexing of semen to increase genetic progress is also examined. Hence, the results are expected to be useful in identifying those advances in reproductive technologies which are likely to be of most value in breeding schemes.

\section{METHODS}

\section{Description of simulations}

The stochastic model to simulate a MOET nucleus scheme for beef cattle has been described in detail by Villanueva et al (1994). The trait under selection was assumed to be recorded in both sexes and around $400 \mathrm{~d}$ of age (between 385 and $415 \mathrm{~d}$ ), at the end of a performance test. The trait was simulated assuming and additive infinitesimal model with an initial heritability of 0.35 . The nucleus was established with 9 males and 18 females of 2, 3 and 4 years of age. The number of animals in each age group was approximately the same. These unrelated individuals constituted the base population. True breeding values of base population animals were obtained from a normal distribution with mean zero and variance $\left(\sigma_{\mathrm{A}}^{2}\right) 0.35$ (different age groups had the same genetic mean). Phenotypic values were obtained by adding a normally distributed environmental component with mean zero and variance 0.65 .

Selection was carried out for 25 years. The number of breeding males and females was constant over years and equal to the number of base males and females (9 sires and 18 donors). Animals were genetically evaluated twice a year (evaluation 
period $=6$ months). Estimated breeding values (EBVs) were obtained using an individual animal model BLUP. The overall mean was the only fixed effect included in the model. Males and females with the highest EBVs were selected and randomly mated according to a nested design. Each sire was used the same number of times in 1 evaluation period. Animals were selected irrespective of whether they had been selected in previous periods and animals not selected were culled from the herd.

True breeding values of the offspring born every year, were generated as

$$
T B V_{\mathrm{i}}=(1 / 2)\left(T B V_{\mathrm{s}}+T B V_{\mathrm{d}}\right)+m_{\mathrm{i}}
$$

where $T B V_{\mathrm{i}}, T B V_{\mathrm{s}}$ and $T B V_{\mathrm{d}}$ are the true breeding values of the individual $\mathrm{i}$, its sire and its dam respectively, and $m_{\mathrm{i}}$ is the Mendelian sampling term. The Mendelian term was obtained from a normal distribution with mean zero and variance $(1 / 2)\left[1-\left(F_{\mathrm{s}}+F_{\mathrm{d}}\right) / 2\right] \sigma_{\mathrm{A}}^{2}$, where $F_{\mathrm{s}}$ and $F_{\mathrm{d}}$ are the inbreeding coefficients of the sire and dam, respectively. The inbreeding coefficients of the animals were obtained from the additive relationship matrix.

Values for reproductive success rates (parameters of embryo yield, frequency of embryo collection and survival rate of transferred embryos) were varied in different schemes. The number of transferable embryos collected per flush and per cow was obtained from a Poisson distribution whose parameter was distributed according to a gamma distribution (Woolliams et al, 1995). This model is described in the next section (Model 1). Different values for the mean number of transferable embryos per flush and per donor, the coefficient of variation and repeatability of embryo yield, the frequency of flushing and the embryo survival rate were considered. Current values were obtained from analyses of extensive data on embryo recovery (Woolliams et al, 1995). Potential future values were obtained from a survey of international experts in reproductive technologies (Luo et al, 1994). All calves were born from embryo transfer, $i e$ there were no calves from natural matings. The survival to birth of a transferred embryo was assigned at random with different probabilities in different schemes $(0.55,0.65$ or 0.75$)$. The sex of the embryos was also assigned at random with probability $1 / 2$ of obtaining a male (expected sex ratio $0^{7 / Q}=1: 1$ ) for most schemes. In order to evaluate the possible benefit of using sexed semen, the ratio was changed to $1: 2$ and 1:3. In these cases, the probability of obtaining a male was $1 / 3$ and $1 / 4$, respectively. Males were assumed capable of breeding after being performance tested. The minimum age of donors was 15 months. At all ages after birth, individuals were subject to a mortality rate that varied with age. Survival probabilities from birth to 3 weeks, 6 months and 2, 5, 10 or 15 years were 0.98 , $0.97,0.96,0.93,0.86$ and 0.00 , respectively. Thus, the maximum age of the animals was 15 years. Survival rates were assumed to be the same for both sexes.

\section{Models for embryo production}

In the present study, the number of embryos produced per flush and per donor was generated using the model proposed by Woolliams et al (1995). In order to investigate the effect of including extra variation in embryo production on rates of response and inbreeding this model was compared with models used in previous studies (fixed number of embryos per collection or variable number of embryos per 
collection but with zero repeatability between flushes). Four different models were analysed.

\section{Model 1}

The model proposed by Woolliams et al (1995) generates the number of embryos produced from a negative binomial distribution (Poisson distribution whose parameter is distributed according to a gamma distribution). The number of embryos collected from the $i$ th donor in the $j$ th flush was sampled from a Poisson distribution whose parameter $\lambda_{i j}$ was sampled from a gamma distribution with shape parameter $\beta_{i}$ and scale parameter $v$. In that way a correlation between the number of embryos produced in successive flushes of a cow is included in the model. The natural logarithm of $\beta_{i}$ (parameter specific for each donor) was sampled from a normal distribution with mean $\mu$ and variance $\sigma^{2}$. The logarithm of $\beta_{i}$ is taken to avoid negative numbers. The maximum value of $\lambda_{i j}$ was set to 30 . Let $y_{i}$ be the number of transferable embryos obtained at the $j$ th collection. Then the expected value and variance of $y_{i}$ are $E\left(y_{i}\right)=\beta_{i} v$ and $\operatorname{Var}\left(y_{i}\right)=\beta_{i} v\left(1+\beta_{i}^{2}\right)$, respectively (Woolliams et al, 1995). In order to explore the effect of changing these key parameters, a simulation program was written to simulate embryo production using this model. The number of donors simulated was 100000 and the number of flushes was 3 for each donor. The repeatability was calculated as $R=\sigma_{\mathrm{B}}^{2} /\left(\sigma_{\mathrm{B}}^{2}+\sigma_{\mathrm{W}}^{2}\right)$, where $\sigma_{\mathrm{B}}^{2}$ is the variance in embryo production among donors and $\sigma_{\mathrm{W}}^{2}$ is the variance among flushes (within donors). The coefficient of variation was calculated as $C V=\left(\sigma_{\mathrm{B}}^{2}+\sigma_{\mathrm{W}}^{2}\right)^{1 / 2} / M E A N$, where $M E A N$ is the overall mean of embryos collected per flush and per donor. The estimates of $\sigma_{\mathrm{B}}^{2}$ and $\sigma_{\mathrm{W}}^{2}$ were obtained from an analysis of variance of simulated data. Current values for embryo production (Luo et al, 1994) correspond to the following parameter values: $\mu=1.46, \sigma^{2}=0.4$ and $v=1.0$. These values led to a mean number of transferable embryos per flush and per donor of 5.0, with a coefficient of variation of 1.28 and repeatability of 0.22 .

\section{Model 2}

The number of embryos collected was obtained in the same way as described in Model 1 but now the logarithm of $\beta_{i}$ was sampled from a normal distribution with mean $\mu$ and variance zero. Since parameter $\beta_{i}$ is a constant, there is no variability among donors and the repeatability of embryo production is zero. The values for the parameters of the distributions were $\mu=1.61, \sigma^{2}=0.0$ and $v=1.0$. These values lead to the same mean number of embryos collected as in Model 1 but to a lower coefficient of variation $(C V=1.09, R=0.00)$.

\section{Model 3}

The number of embryos collected per flush and per donor was generated by sampling from a strict Poisson distribution with parameter 5 . The variability of embryo yield was therefore lower than in Model $2(C V=0.45, R=0.00)$. 


\section{Model 4}

Finally, a model in which a constant number of embryos collected per flush and per donor (5 embryos) was considered $(C V=R=0.00)$.

Figure 1 shows the distribution of the number of transferable embryos under the first 3 models.

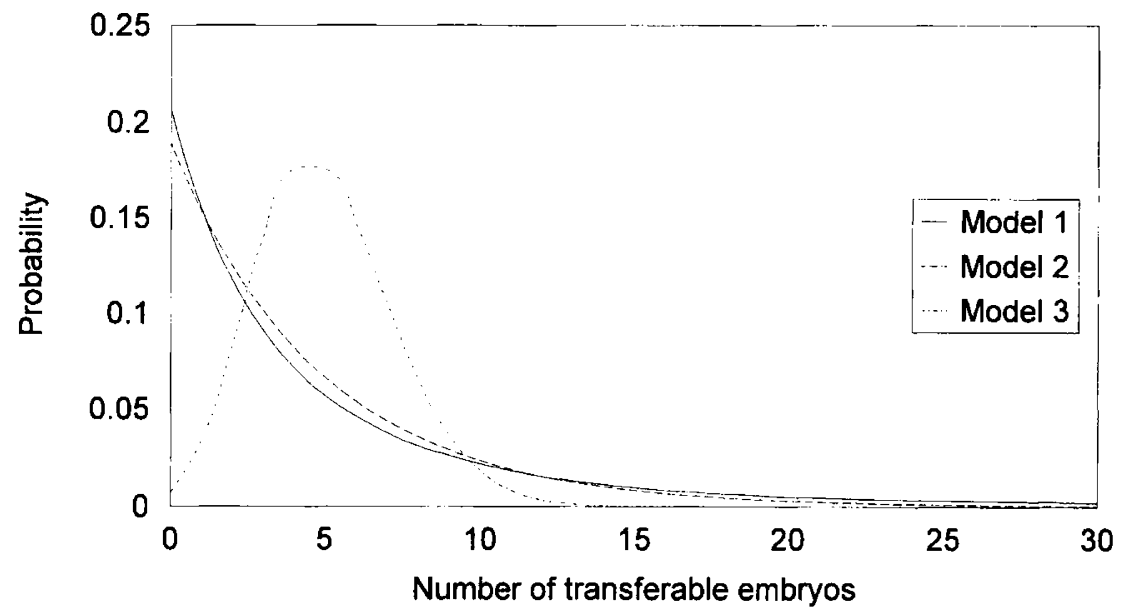

Fig 1. The distribution of the number of transferable embryos per flush and per donor under different models for embryo yield.

\section{Comparison among breeding schemes}

The scheme with current values for reproductive parameters was used as a point of reference for comparisons. Average true breeding values $\left(G_{i}\right)$ and inbreeding coefficients $\left(F_{i}\right)$ of individuals born at the $i$ th year were obtained. Annual rate of response between years $j$ and $i$ was calculated as $\Delta G_{i-j}=\left(G_{j}-G_{i}\right) /(j-i)$, where $j>i$. Rates of inbreeding were obtained every year as $\Delta F_{i}=\left(F_{i}-F_{i-1}\right) /\left(1-F_{i-1}\right)$. The rate of inbreeding between years $j$ and $i\left(\Delta F_{i-j}\right)$ was obtained by taking the average of annual rates. Also, the following parameters were calculated in the simulations: 1) genetic variance of animals born every year; 2) accuracy of selection (correlation between the true breeding values and selection criteria of the candidates for selection); 3) genetic selection differentials (difference between the mean values of selection criteria of selected individuals and candidates for selection) and selection intensities for males and females; 4) generation intervals (average age of parents when offspring are born) for males and females; and 5) variance of family sizes for male and female parents. The latter was calculated as described in Villanueva et al (1994). Each scheme was replicated 200 times and the values presented are the average over all replicates. The criteria for comparing different schemes were the rates of response $\left(\Delta G_{15-25}\right)$ and inbreeding $\left(\Delta F_{15-25}\right)$ at the later years (from year 15 to year 25$)$. The cumulative response $\left(G_{25}\right)$ and inbreeding at year $25\left(F_{25}\right)$ were also compared. 


\section{RESULTS}

\section{Models for embryo production}

Table I shows the genetic progress and the inbreeding obtained under different models used to generate the number of embryos per collection. The results show that the inbreeding obtained depended on the values of the coefficient of variation and the repeatability of embryo yield. By making the correlation between embryo production at different recoveries equal to zero $(R=0.00)$, the rate of inbreeding decreased by $4 \%$ (Models 1 and 2). The effect of the coefficient of variation of embryo yield on the rate of inbreeding was notable. By increasing the coefficient of variation by a factor of 2.4 the rate of inbreeding increased by $14 \%$ (Models 2 and 3). The rate of inbreeding obtained when the number of embryos collected was fixed (Model 4) was between 2 and $14 \%$ lower than that obtained when there was variability in embryo yield but the repeatability was zero (Models 3 and 2). The genetic progress decreased as variability of embryo production increased. The decrease in response was however small. The genetic gain obtained with Model 1 was around $2 \%$ lower than that obtained with Model 4 (fixed number of embryos).

Table I. Genetic progress (phenotypic standard deviation units) and inbreeding (\%) and their standard errors using different models to generate the number of embryos collected per flush and per donor ${ }^{\mathrm{a}}$.

\begin{tabular}{lccccc}
\hline \multirow{2}{*}{ Model $^{\mathrm{b}}$} & \multicolumn{2}{c}{ Genetic progress } & & \multicolumn{2}{c}{ Inbreeding } \\
\cline { 2 - 3 } \cline { 5 - 6 } & $\Delta \mathrm{G}_{15-25}$ & $\mathrm{G}_{25}$ & & $\Delta \mathrm{F}_{15-25}$ & $\mathrm{~F}_{25}$ \\
\hline Model 1 & $0.199(0.002)$ & $4.85(0.03)$ & & $1.98(0.07)$ & $40.54(0.53)$ \\
Model 2 & $0.203(0.002)$ & $4.89(0.02)$ & & $1.90(0.06)$ & $38.61(0.55)$ \\
Model 3 & $0.201(0.001)$ & $4.92(0.03)$ & & $1.67(0.05)$ & $35.72(0.45)$ \\
Model 4 & $0.204(0.002)$ & $4.92(0.03)$ & & $1.64(0.05)$ & $35.23(0.50)$ \\
\hline
\end{tabular}

${ }^{\mathrm{a}}$ Standard errors are shown in brackets; ${ }^{\mathrm{b}}$ Model 1: Poisson with variable parameter $(M E A N=5.0, C V=1.28, R=0.22)$. Model 2: Poisson with variable parameter $M E A N=5.0, C V=1.09, R=0.00)$. Model 3: Poisson with constant parameter $(M E A N=5.0, C V=0.45, R=0.00)$. Model 4: fixed number of embryos $(M E A N=5.0$, $C V=0.00, R=0.00)$.

\section{Improved embryo recovery and embryo transfer}

Values for reproductive parameters utilized in different schemes are shown in table II. Two different situations of improved technology for embryo production were considered. Firstly, the coefficient of variation of embryo yield was decreased and the mean was maintained. Secondly, the coefficient of variation was decreased and the mean was increased. Under Model 1, the coefficient of variation can be decreased by increasing $v$ since $C V=\left[\left(1+\beta_{i}^{2}\right) / \beta_{i} v\right]^{1 / 2}$. In order to keep the mean constant, $\beta_{i}$ must be decreased, which is achieved by decreasing $\mu$. In the second situation (coefficient of variation decreased and mean increased) the parameter $v$ 
Table II. Values for reproductive parameters used in the simulations.

\begin{tabular}{lcc}
\hline Parameter & Current value & Future values \\
\hline $\begin{array}{l}\text { Mean number of transferable embryos } \\
\text { per flush and donor }(M E A N)\end{array}$ & 5.0 & $7.4,9.6$ \\
Coefficient of variation of embryo & & \\
production $(C V)$ & 1.28 & $1.10,1.07,1.05,0.91$ \\
Repeatability of embryo production $(R)$ & 0.22 & $0.34,0.38,0.29,0.35$ \\
Frequency of flushing in days between flushes $(F C)$ & 60 & 45 \\
Embryo survival rate $(E S R)$ & 0.55 & $0.65,0.75$ \\
\hline
\end{tabular}

Table III. Values of embryo distribution parameters used in the simulations and expected mean $(M E A N)$, coefficient of variation $(C V)$ and repeatability $(R)$ of embryo yield.

\begin{tabular}{ccccccc}
\hline & \multicolumn{2}{c}{ Distribution parameter } & & \multicolumn{3}{c}{ Embryo yield parameter } \\
& $\mu$ & $\sigma^{2}$ & & MEAN & CV & $\mathrm{R}$ \\
\hline 1.0 & 1.46 & 0.4 & & 5.0 & 1.28 & 0.22 \\
2.0 & 0.77 & 0.4 & & 5.0 & 1.10 & 0.34 \\
2.5 & 0.50 & 0.4 & & 5.0 & 1.07 & 0.38 \\
1.5 & 1.46 & 0.4 & & 7.4 & 1.05 & 0.29 \\
2.0 & 1.46 & 0.4 & & 9.6 & 0.91 & 0.35 \\
\hline
\end{tabular}

was increased whereas $\mu$ was kept constant. Values used for embryo distribution parameters as well as the resulting $M E A N, C V$ and $R$ are shown in table III.

The rates of response and inbreeding obtained with improved values for parameters of embryo recovery and embryo transfer are shown in table IV. The first row of the table represents the current situation and is used as a reference. The expected number of embryos transferred for each scheme is shown in the last column. Decreasing the coefficient of variation of embryo production while keeping the mean approximately constant did not have an effect on rates of response and inbreeding. This may be due to the increased repeatability that accompanied the decrease in $C V$ in the model. The influence of the repeatability of embryo yield has been shown in the previous section. Increasing the mean number of embryos transferred led to a notable increase in the rates of response, due to increased selection intensities and accuracy and decreased generation intervals. In this case, the number of calves born per year $\left(N_{\mathrm{CB}}\right)$ was unrestricted and the number of donors was constant, so increasing embryo yield led to more candidates for selection. Male and female selection intensities $\left(i_{\circlearrowleft}\right.$ and $\left.i_{\odot}\right)$ and generation intervals $\left(L_{\circlearrowleft}\right.$ and $\left.L_{\odot}\right)$ are shown in table $\mathrm{V}$. The rate of inbreeding (per year and per generation) was also increased (particularly when the mean number of embryos produced was 9.6) due to increased full-sib family sizes and intensities of selection and decreased generation intervals.

The assumed current frequency of collection of embryos $(F C)$ was $60 \mathrm{~d}$ (3 flushes in a 6 month period). The potential benefits from increasing the frequency of 


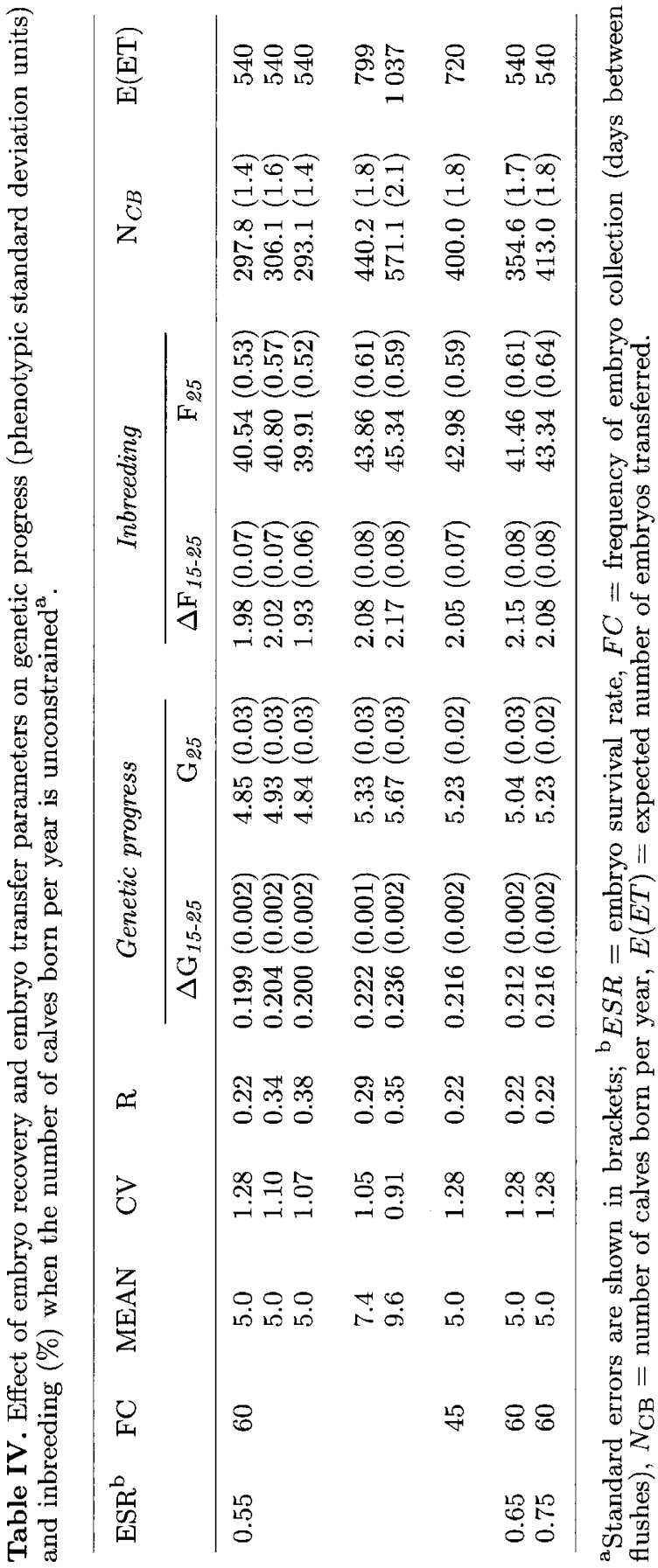


Table V. Effect of embryo recovery and embryo transfer parameters on selection intensities $\left(i_{\circlearrowleft}\right.$ and $\left.i_{q}\right)$ and generation intervals $\left(L_{\circlearrowleft}\right.$ and $\left.L_{\odot}\right)$ when the number of calves born per year is unconstrained ${ }^{a}$.

\begin{tabular}{ccccccccc}
\hline ESR $^{\mathrm{b}}$ & FC & MEAN & $\mathrm{CV}$ & $\mathrm{R}$ & $\mathrm{i}_{\Im}$ & io & $\mathrm{L}_{\circlearrowleft}$ & $\mathrm{L}_{\odot}$ \\
\hline 0.55 & 60 & 5.0 & 1.28 & 0.22 & $1.62(0.005)$ & $1.35(0.004)$ & $2.95(0.007)$ & $3.15(0.006)$ \\
& & 5.0 & 1.10 & 0.34 & $1.64(0.005)$ & $1.37(0.004)$ & $2.94(0.007)$ & $3.14(0.006)$ \\
& & 5.0 & 1.07 & 0.38 & $1.62(0.005)$ & $1.35(0.004)$ & $2.96(0.007)$ & $3.15(0.006)$ \\
& & 7.4 & 1.05 & 0.29 & $1.80(0.005)$ & $1.52(0.004)$ & $2.84(0.006)$ & $3.03(0.005)$ \\
& & 9.6 & 0.91 & 0.35 & $1.91(0.004)$ & $1.64(0.004)$ & $2.80(0.005)$ & $2.97(0.004)$ \\
0.65 & 65 & 5.0 & 1.28 & 0.22 & $1.76(0.005)$ & $1.48(0.004)$ & $2.87(0.007)$ & $3.05(0.006)$ \\
0.75 & 60 & 5.0 & 1.28 & 0.22 & $1.70(0.005)$ & $1.43(0.004)$ & $2.89(0.005)$ & $3.09(0.005)$ \\
& & & 1.28 & 0.22 & $1.76(0.005)$ & $1.49(0.004)$ & $2.86(0.006)$ & $3.05(0.006)$ \\
\hline
\end{tabular}

${ }^{\text {a }}$ Standard errors are shown in brackets. ${ }^{\mathrm{b}} E S R=$ embryo survival rate, $F C=$ frequency of embryo collection (days between flushes).

flushing to $45 \mathrm{~d}$ ( 4 flushes in a 6 month period) on rates of response and inbreeding are also shown in table IV. The increase in flushing frequency to this optimistic future value produced a clear increase in genetic progress. This increase in genetic progress was due to increased selection intensities and accuracy of selection and decreased generation intervals (table V). Inbreeding was slightly higher when donors were flushed 4 times per period. Finally, by increasing the probability that an embryo survives until calving (ESR) from 0.55 to 0.65 and 0.75 , cumulative genetic response was increased by 4 and $8 \%$, respectively. The rate of inbreeding was also increased. Table $\mathrm{V}$ indicates increases in selection intensities and decreases in generation intervals with improved viability of the embryos.

Tables IV and V show results obtained without a constraint on the number of calves born in the scheme. By increasing the mean number of embryos per flush and per donor, the frequency of flushing or the embryo survival probability, the expected number of offspring is increased. Genetic progress obtained at year 25 was directly proportional to the number of calves born each year (table IV). With more offspring born, the selection intensities and the accuracy of selection were increased and the generation intervals were decreased (table V). Also, the rate of inbreeding (per year and per generation) was increased by improving embryo transfer and embryo recovery techniques. For a fixed number of sires and donors, the increase in the number of offspring born per year led to an increase in the variances of family sizes.

Comparing schemes which differ widely in the number of offspring produced is unfair. This is because genetic gains are expected to be higher (and inbreeding is expected to be lower) in larger schemes, irrespective of the use of breeding technologies. Also, in practice, there will usually be a limitation on the number of embryo collections or transfers which can be made, the number of recipients available, or the number of testing places available for calves. These constraints are equivalent, except when different success rates are assumed for embryo technologies. 
Simulations were therefore also run with a restriction on the number of offspring born every year and the results are presented in table VI.

When the mean number of embryos collected per flush and the frequency of collection were increased, some embryos were discarded in order to transfer a fixed number. In these cases, the expected average number of embryo transfers per year was 540 (this is the expected number of transfers with current values for reproductive parameters and 18 donors). Embryos were not discarded at random; most were discarded from donors producing more embryos, in order to equalize family sizes. The decision on which embryos were transferred was made within individual flushes. First, the number of embryos recovered from each donor was obtained using Model 1. After that, 1 embryo from each donor (if available) was allocated (for transfer) in succession and this process was repeated until the desired total number of embryos was reached. In these cases, the maximum number of embryos transferred after a single flush was $18 \times 5=90$. When the survival rate of embryos from transfer until birth was increased, the number of transfers was decreased in order to obtain a fixed number of calves born per year. Again, more embryos were discarded from donors with higher embryo production. Table VI shows that with these strategies, the number of calves born per year $\left(N_{\mathrm{CB}}\right)$ was approximately constant in all schemes.

Increasing the mean number of embryos produced per flush and per donor from 5.0 to 7.4 and 9.6 decreased the rate of inbreeding by up to $10 \%$ even with the increased repeatability (table VI). Thus, restricting family sizes nullified the effect of repeatability. The decrease in inbreeding rates was due to decreased variances of family sizes. The increase in frequency of flushing also led to a decrease in the rate of inbreeding (by $11 \%$ ) whereas the genetic progress was not affected. Finally, by increasing the probability of embryo survival, the rate of inbreeding was reduced by up to $5 \%$ with no effect on response. These latter schemes $(E S R>0.55)$ were not compared on an equal basis with the others, since fewer embryos were transferred and less recipients were used.

\section{Sexing of semen}

Table VII shows the results obtained when sexed semen was used to change the sex ratio from 1:1 to $1: 2$ and 1:3 in favour of females, in order to increase the selection intensity in this sex. The number of embryos obtained per flush and per donor was simulated using Model 1. The number of transfers per year was expected to be the same for all schemes ( 540 transfers per year). There was no benefit from using sexed semen when the number of progeny tested per year was fixed. Table VIII shows generation intervals and selection intensities for schemes with different sex ratios. As expected, the selection intensity of females increases as the proportion of female offspring increases. However, at the same time, there is a reduction in the selection intensity of males and the average selection intensity is not increased. This led to similar rates of response when different sex ratios were simulated. Generation intervals were very similar for schemes with different sex ratios. 


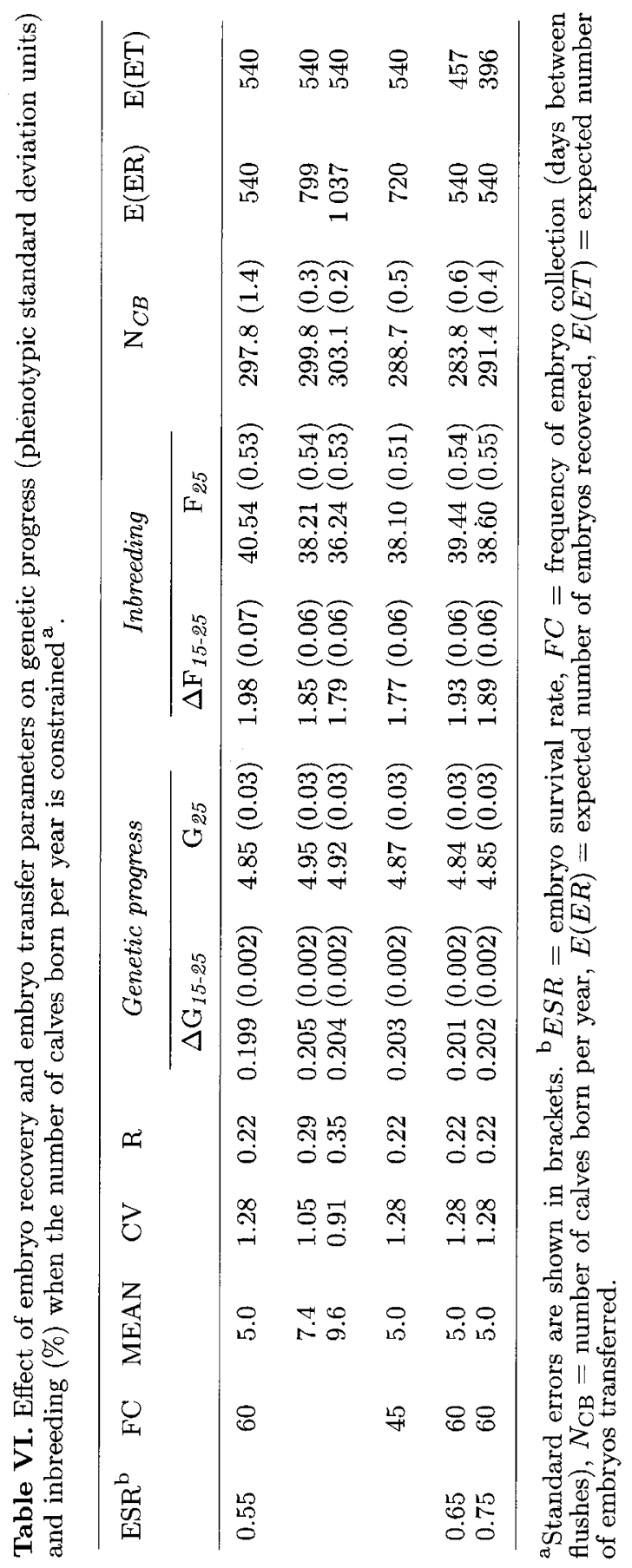


Table VII. Effect of sexing of semen on genetic progress (phenotypic standard deviation units) and inbreeding (\%) ${ }^{\mathrm{a}}$.

\begin{tabular}{lccccc}
\hline \multirow{2}{*}{ Sex ratio $\left(\mathrm{O}^{\top} / Q\right)$} & \multicolumn{2}{c}{ Genetic progress } & & \multicolumn{2}{c}{ Inbreeding } \\
\cline { 2 - 3 } \cline { 5 - 6 } & $\Delta \mathrm{G}_{15-25}$ & $\mathrm{G}_{25}$ & & $\Delta \mathrm{F}_{15-25}$ & $\mathrm{~F}_{25}$ \\
\hline $1: 1$ & $0.199(0.002)$ & $4.85(0.03)$ & & $1.98(0.07)$ & $40.54(0.53)$ \\
$1: 2$ & $0.200(0.002)$ & $4.83(0.03)$ & & $2.09(0.07)$ & $41.90(0.55)$ \\
$1: 3$ & $0.195(0.002)$ & $4.70(0.03)$ & & $2.03(0.07)$ & $40.79(0.61)$ \\
\hline
\end{tabular}

${ }^{\text {a }}$ Standard errors are shown in brackets.

Table VIII. Effect of sexing of semen on selection intensities ( $i_{\odot}$ and $\left.i_{\rho}\right)$ and generation intervals $\left(L_{\circlearrowleft}\right.$ and $\left.L_{\odot}\right)$ a.

\begin{tabular}{lcccc}
\hline Sex ratio $\left(\circlearrowleft^{\prime} / \uparrow\right)$ & $\mathrm{i}_{\Im}$ & i & $\mathrm{L}_{\circlearrowleft}$ & $\mathrm{L}_{q}$ \\
\hline $1: 1$ & $1.62(0.005)$ & $1.35(0.004)$ & $2.95(0.007)$ & $3.15(0.006)$ \\
$1: 2$ & $1.44(0.004)$ & $1.49(0.004)$ & $2.99(0.007)$ & $3.11(0.006)$ \\
$1: 3$ & $1.30(0.004)$ & $1.54(0.004)$ & $3.04(0.007)$ & $3.13(0.007)$ \\
\hline
\end{tabular}

${ }^{\text {a }}$ Standard errors are shown in brackets.

\section{DISCUSSION}

Two novelties of the present study are that the coefficient of variation of embryo yield used corresponds to that observed in real data (and is higher than that used in previous studies) and that the repeatability of embryo yield has been included. Studies evaluating the use of MOET for genetic improvement of ruminants have frequently assumed a fixed number of embryos per collection (Land and Hill, 1975; Nicholas and Smith, 1983; Juga and Mäki-Tanila, 1987; Gearheart et al, 1989; Keller et al, 1990; Meuwissen, 1991; Ruane and Thompson, 1991; Toro et al, 1991; Bondoc and Smith, 1993; Leitch et al, 1994). Several studies have considered variable family sizes but using hypothetical distributions.

Ruane (1991) simulated variable family sizes by obtaining the number of embryos recovered per donor from a normal distribution with mean 16 and variance up to 64 (he assumed 4 flushes per generation and an average of 4 embryos per flush). Thus the highest coefficient of variation for embryo production simulated was 0.50 . His results showed a small effect of variation in family sizes on rates of response and inbreeding. The reduction in response by including variation in the number of embryos collected per donor was around $4 \%$ whereas the increase in inbreeding was up to $3 \%$. Colleau (1991) used a 'scaled' binomial distribution to model embryo production. The proportion of treated cows responding to superovulation $(p)$ was 0.7 and the number of embryos collected per flush and per treated cow $(m)$ was 4 or 5 . Thus the number of embryos collected per flush and per donor was $m \theta$, where $\theta$ is a random variable having a binomial distribution with the parameters $n=1$ (flushes) and $p=0.7$ (probability of a successful flush). The mean of this 
distribution is $m n p$ and the variance is $m^{2} n p(1-p)$ which leads to a coefficient of variation of $[(1-p) / p]^{1 / 2}=0.65$. Poisson distributions (with constant parameters) have been used also for modelling the number of embryos recovered following superovulation. Schrooten and van Arendonk (1992) used a Poisson distribution with parameter 5 to obtain the number of live calves per flush. This implies a coefficient of variation of 0.45 .

More realistic models have been proposed to generate embryo yield distributions (Foulley and Im, 1993; Tempelman and Gianola, 1993; 1994). In a simulation study, Tempelman and Gianola (1994) generated embryo yields in MOET nucleus herds using a model which includes repeatable variation among donors. Withindam variation was modelled using a Poisson distribution. However, Woolliams et al (1995) have shown that extra-Poisson variation is observed in practice. Actual data on ovulation rates and embryo recoveries are better described by negative binomial distributions than by Poisson models. In the model of Tempelman and Gianola (1994), more within-donor variation could be generated by including an additional random term.

Wray and Simm (1990) used a distribution based on commercial data to generate the number of calves per flush in beef cattle. The coefficient of variation used was 1.15. The coefficient of variation of the number of calves born per flush can be obtained from the mean and the coefficient of variation of embryo yield as

$$
\left[E S R(1-E S R) M E A N+E S R^{2} C V^{2} M E A N^{2}\right]^{1 / 2} /[E S R \times M E A N]
$$

The value used in the present study (1.34) is higher than that used in previous studies. Changes in inbreeding also depend on the value of repeatability of embryo yield (table I). With increased repeatability of embryo yield, an increase in the variance of family size is expected (since the variance between donors increases), with the potential for fewer families to make a greater contributions to successive generations. Thus, models used previously (which have assumed a constant number of embryos per collection or a variable number, but with lower coefficient of variation and no correlation between different recoveries) have underestimated the rate of inbreeding and overestimated genetic gain.

Improved embryo recovery and transfer success rates lead to higher rates of response and inbreeding than current success rates, providing the number of calves tested per year is unconstrained. This is due to higher selection intensities and accuracies, lower generation intervals and higher and more variable family sizes. However, it is unrealistic to assume unconstrained number of calves born since, in centralized nucleus herds, costs will depend of the total number of animals in the scheme. When different schemes are compared at a constant number of offspring born per year, improved success rates do not increase progress, since selection intensities and generation intervals are maintained. However, inbreeding rates can be markedly reduced by discarding more embryos from donors with the highest embryo production, to equalize family sizes. Although the results presented are for the later years of selection, rates of response and inbreeding were also obtained for the early years (from year 5 to year 15). There was no significant effect of time on the results of comparisons among schemes.

Schemes which assumed improved embryo transfer techniques (improved ESR) require less recipients, and therefore, should have lower costs than the rest of the 
schemes (see $E(E T)$ in table VI). An alternative basis for making fair comparisons would be to transfer 540 embryos and, from the $351(E S R=0.65)$ and 405 $(E S R=0.75)$ calves expected, choose for performance testing the 297 animals which would best equalize family sizes. In this case, schemes with improved $E S R$ could benefit from selling surplus calves. On the other hand, improved embryo recovery techniques (increased $M E A N$ and $F C$ ) give the opportunity of selling surplus embryos (see $E(E R)$ in table VI). However, this benefit is difficult to quantify as there is not currently a large or stable market for beef cattle embryos.

Variation in response to selection can be an important limitation of MOET nucleus schemes. Nicholas (1989) suggested that the maximum acceptable coefficient of variation of response after 10 years of selection ranged from 5 to $10 \%$. For the schemes considered in this paper, the coefficients of variation of response over a 10 year period varied from 10 to $14 \%$. Thus, the size of the nucleus needs to be larger than that considered here, or strategies for controlling inbreeding should be applied, to have a reasonable level of risk.

In breeding programmes, sexing of embryos or semen could be used to increase the selection intensity applied to females. However, there seems to be no benefit from sexing when performance information is available on both sexes and comparisons are made at a fixed number of individuals tested per year (table VII). As expected, the selection intensity of females increased as the proportion of female offspring increased. However, at the same time, there was a reduction in the selection intensity of males and the overall selection intensity was unchanged (table VIII). Wray and Goddard (1994) have investigated a different strategy, in sheep MOET schemes, which used sexed semen (female) to inseminate the selected dams with lower EBVs whereas the top selected dams were inseminated with unsexed semen (to avoid decreases in male selection intensity). However, in MOET schemes, the overall selection intensity did not change. They found a benefit from sexing in conventional schemes (without MOET), suggesting that sexing can be beneficial when the male and female selection intensities differ greatly.

On the other hand, Colleau (1991) reported, for dairy cattle, slightly higher gains for adult MOET schemes with sexing of embryos than for juvenile MOET schemes without sexing. Since juvenile schemes are expected to be superior to adult schemes without sexing (with respect to genetic progress), his results suggest a clear benefit from sexing. Whereas the studies discussed in the previous paragraph have considered fixed numbers of transfers, sires and dams, Colleau's model allowed the number of dams to vary. The nucleus considered assumed females dispersed across many recorded herds. For his adult scheme, the overall number of dams used for replacements was much higher than in the juvenile scheme. This allowed selection differentials in the adult scheme to be high enough to compensate for the longer generation intervals. In centralized nucleus schemes, a constraint on the number of dams would be also needed. In these circumstances the advantage of sexing would be doubtful.

In conclusion, the values of the coefficient of variation and the repeatability of embryo yield are important in determining rates of inbreeding. When the number of testing places is constrained, improved technologies can greatly decrease the rate of inbreeding without affecting genetic gain. Finally, when performance information 
is available on both sexes and comparisons are carried out at a fixed number of individuals tested per year, there is no apparent benefit in response from sexing.

\section{ACKNOWLEDGMENTS}

We would like to thank Drs B McGuirk, R Thompson and a referee for their valuable suggestions. This work was funded by the Ministry of Agriculture, Fisheries and Food, the Milk Marketing Board of England and Wales and the Meat and Livestock Commission. SAC receives financial support from the Scottish Office Agriculture and Fisheries Department and the Roslin Institute receives financial support from the Biotechnology and Biological Sciences Research Council and the Ministry of Agriculture, Fisheries and Food.

\section{REFERENCES}

Bondoc OL, Smith C (1993) Optimized testing schemes using nucleus progeny, adult MOET siblings, or juvenile MOET pedigrees in dairy cattle closed populations. $J$ Anim Breed Genet 101, 30-40

Colleau JJ (1991) Using embryo sexing within closed mixed multiple ovulation and embryo transfer schemes for selection of dairy cattle. J Dairy Sci 74, 3973-3984

Dekkers JCM (1992) Structure of breeding programs to capitalize on reproductive technology for genetic improvement. J Dairy Sci 75, 2880-2891

Foulley JL, Im S (1993) A marginal quasi-likelihood approach to the analysis of Poisson variables with generalized linear mixed models. Genet Sel Evol 25, 101-107

Gearheart WW, Smith C, Teepker G (1989) Multiple ovulation and embryo manipulation in the improvement of beef cattle: relative theoretical rates of genetic change. J Anim Sci $67,2863-2871$

Juga J, Mäki-Tanila (1987) Genetic change in a nucleus breeding dairy herd using embryo transfer. Acta Agric Scand 37, 511-519

Keller DS, Gearheart WW, Smith C (1990) A comparison of factors reducing selection response in closed nucleus breeding schemes. J Anim Sci 68, 1553-1561

Land RB, Hill WG (1975) The possible use of superovulation and embryo transfer in cattle to increase response to selection. Anim Prod 21, 1-12

Leitch HW, Smith C, Burnside EB, Quinton M (1994) Genetic response and inbreeding with different selection methods and mating designs for nucleus breeding programs of dairy cattle. J Dairy Sci 77, 1702-1718

Lohuis MM, Smith C, Dekkers JCM (1993) MOET results from a dispersed hybrid nucleus programme in dairy cattle. Anim Prod 57, 369-378

Luo ZW, Woolliams JA, Simm G (1994) An assessment of present and future effectiveness of embryological techniques in ruminants. Agric Biotech News Infor 6, 13N-18N

Meuwissen THE (1991) The use of increased female reproductive rates in dairy cattle breeding schemes. Anim Prod 52, 21-31

Nicholas FW (1989) Incorporation of new reproductive technology in genetic improvement programmes. In: Evolution and Animal Breeding (WG Hill, FC MacKay, eds), CBA International, Wallingford, UK, 203-209

Nicholas FW, Smith C (1983) Increased rates of genetic changes in dairy cattle by embryo transfer and splitting. Anim Prod 36, 341-353

Ruane J (1991) The importance of family sizes in adult multiple ovulation and embryo transfer (MOET) nucleus breeding schemes in dairy cattle. Anim Prod 52, 33-47 
Ruane T, Thompson R (1991) Comparison of simulated and theoretical results in adult MOET nucleus schemes for dairy cattle. Livest Prod Sci 28, 1-20

Schrooten C, van Arendonk JAM (1992) Stochastic simulation of dairy cattle breeding schemes: genetic evaluation of nucleus size and type. J Anim Breed Genet 109, 1-15

Smith C (1986) Use of embryo transfer in genetic improvement of sheep. Anim Prod 42, 81-88

Tempelman RJ, Gianola D (1993) Marginal maximum likelihood estimation of variance components in Poisson mixed models using Laplacian integration. Genet Sel Evol 25, 305-319

Tempelman RJ, Gianola D (1994) Assessment of a Poisson animal model for embryo yield in a simulated multiple ovulation-embryo transfer scheme. Genet Sel Evol 26, 263-290

Toro M, Silió L, Perez-Enciso M (1991) A note on the use of mate selection in closed MOET breeding schemes. Anim Prod 53, 403-406

Villanueva B, Woolliams JA, Simm G (1994) Strategies for controlling rates of inbreeding in MOET nucleus schemes for beef cattle. Genet Sel Evol 26, 517-535

Woolliams JA, Luo ZW, Villanueva B et al (1995) Analysis of factors affecting superovulatory responses in ruminants. J Agric Sci, Camb 124, 61-70

Way NR, Goddard ME (1994) MOET breeding schemes for wool sheep. I. Design alternatives. Anim Prod 59, 71-86

Wray NR, Simm G (1990) The use of embryo transfer to accelerate genetic improvement in beef cattle. In: Proceedings of the 4th World Congress on Genetics Applied to Livestock Production, Vol XV, Edinburgh, 23-27 July (WG Hill, R Thompson, JA Woolliams, eds), 315-318 